INTERNATIONAL JOURNAL OF MULTIDisciplinARY RESEARCH AND ANALYSis

ISSN(print): 2643-9840, ISSN(online): 2643-9875

Volume 04 Issue 06 June 2021

DOI: 10.47191/ijmra/v4-i6-15, Impact Factor: 6.072

Page No.- 779-784

\title{
Interactive Methods in Shaping Music Literacy in Primary School Students
}

\section{Dilshoda Rakhmonova}

Lecturer, Faculty of Art History Department of Music Education Termez State University

ABSTRACT: This article is more effective than interactive methods, taking into account the psychological literacy of teachers and students in the organization of music clubs, as well as the minutes of music literacy in the primary school "Music Culture" lessons in general secondary schools and targeted use, to compose musical impressions and develop the necessary musical knowledge and skills, to teach music literacy or lessons in an orderly, step-by-step manner, from simple to complex, to use time efficiently. As a result, ways to achieve musical literacy are shown.

KEYWORDS: interactive methods, account, psychological literacy, teachers, students, organization, music clubs, primary school, secondary schools, musical impressions, necessary musical knowledge, skills.

"If the teaching methods in the school do not change, the quality, content and environment of education will not change."

\section{INTRODUCTION}

\section{Shavkat Mirziyoyev}

The future of every nation depends on the education of our young generation today, on their development into aesthetically pleasing, cultured, mature and well-rounded people. Carrying out such a responsible task requires modern teachers, especially music culture teachers, to improve their professional skills, understand the essence of advanced pedagogical technologies and use them effectively in their lessons. A modern teacher must have a thorough knowledge of advanced pedagogical technologies in the educational process, be able to analyze and implement them in practice.

President of the Republic of Uzbekistan Shavkat Mirziyoyev chaired a video conference on November 2, 2020 to discuss issues of improving the education system and accelerating the development of science in the country. In the discussion, it was noted that "it is necessary to create a methodology that encourages students not only to memorize, but also to think and think". In order to become cultured, mature and well-rounded people, it is necessary for modern science teachers, including music culture teachers, to improve their professional skills, understand the essence of advanced pedagogical technologies and use them effectively in their lessons.

\section{THE MAIN FINDINGS AND RESULTS}

A modern teacher must have a thorough knowledge of advanced pedagogical technologies in the educational process, be able to analyze and implement them in practice.

The foundation of music education is formed in students in primary school. Therefore, from the 1st grade onwards, the main task is to get students interested in music, to compose musical impressions and to develop the necessary musical skills and abilities.

The performance of these tasks depends in many ways on the knowledge and skills of the teacher. Education in a person with independent critical thinking skills, always ready to learn new things, not afraid of cooperation, free to communicate in an era of rapid increase in the flow of information, the rapid introduction of various innovations in our lives should be the main goal of the process, and opening the way for the application of new technologies in education in this regard is the right step towards achieving the goal.

General secondary school primary music culture classes are organized in 5 types of activities. These are; 


\section{Interactive Methods in Shaping Music Literacy in Primary School Students}

1. Singing in a choir

2. Music literacy

3. Listen to music

4. Musical creativity

5. Perform actions appropriate to the music.

The second "Music Literacy" is a minute of musical literacy and methodological assistance in the use of innovative pedagogical technologies aimed at increasing the knowledge and activity of teachers and students in the organization of music clubs and their application in practice. Teaching is taught in the classroom, in a simple, straightforward, in-depth manner. There is no clear source or training for organizing and conducting music clubs. 45-minute music culture is the goal and task of the lesson, and in its gradual development, special attention is paid to musical literacy. As a result, students do not have the opportunity to acquire sufficient knowledge in music literacy classes, and in the upper grades, the knowledge potential of students in the field of music literacy is significantly reduced. Based on the principle of simplicity to complexity taught in music literacy throughout the course; starting with the five main lines, knowing the keys to music, their location, notes and their division, dynamic and alteration signs, memorizing their rules, and having difficulty reading lead to a lack of knowledge of music literacy in the future. And the knowledge that is given in its place will surely show results in the future.

As a result of our research, taking into account these problems and some shortcomings, the effective and purposeful use of interactive methods, taking into account the psychological and physiological aspects of teachers and students in the minutes of music literacy in the lessons of "Music Culture", to compose musical impressions and to develop the necessary musical skills and competencies, to be taught in musical literacy or lessons in an orderly, step-by-step manner, in what order? From simplicity to complexity, as a result of the efficient use of time, we have laid the groundwork for the explanation and memorization of musical literacy on the basis of musical puzzles, in the form of various games, through beautiful lettering methods, especially with the help of poetic rhymes. We have developed a textbook "Musical Literacy of Secondary School Students". We will show you how to organize, teach one of the lessons in the textbook, and how to achieve results in teaching the type of music literacy activity in the course of the lesson, music lessons.

In music literacy classes, music literacy and theoretical and practical classes in music clubs, teachers need to develop the content and pedagogical technology for organizing practical work that allows students to work independently and creatively. In addition, it is necessary to make effective use of various pedagogical technologies, ie interactive methods. Interactive (English word means to interact). Types of interactions in interactive methods:

Teacher-student;

Student-student;

Teacher-students;

Student-students;

Student-students;

Student-teacher;

In teaching music literacy in music culture classes, we considered it appropriate to use the interactive method of teaching 1-Cognitive (cognito - Latin word, meaning knowledge, knowledge) - interactive method. It is a method that focuses primarily on the formation of students' thinking, which in one form or another involves the organization of group discussions. In addition, Facilitation 2 (English facililitate - facilitation) - the organization of group work, often related to specific, real tasks, decisionmaking, discussion, development of a realistic plan of action, coordination of real, conflicting interests we have chosen the techniques associated with the organization. These two methods can be used effectively and efficiently in teaching basic music literacy.

For example, the topic of the 1st quarter of the 1st grade music culture lesson, topic 10-11, is "Violin key". What is the key to the violin in the textbook for students on this topic? what is the key its functions, writing procedures and stages are not fully explained and explained in a satisfactory manner. The minute of musical literacy is marked as "Violin key, its spelling, the position of the violin key in the note path". But here's the question. How can music literacy be organized based on information and concepts that are not fully covered in the new topic statement? There are no specific assignments and tasks in the book on musical literacy. This situation has been repeated on similar topics. 


\section{Interactive Methods in Shaping Music Literacy in Primary School Students}

Figure 1

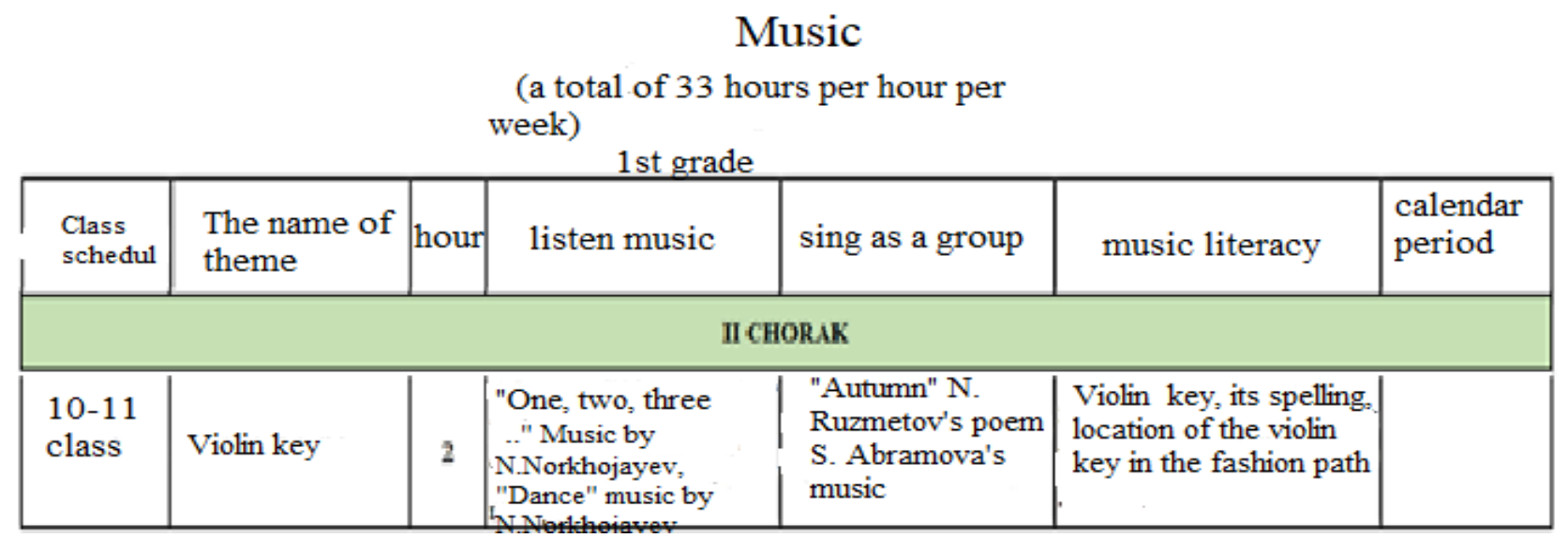

Taking into account these problems and shortcomings, based on the above Cognitive and Facilitating interactive methods, we will provide additional training on the topic "Violin key" in the 2nd quarter of the 1st grade music culture lesson as an additional methodological aid in music literacy. In the manual we have chosen the topic of the lesson "Studying the placement of the violin key in the notation and working on the elements" and give methodological recommendations in this regard.

Let me remind you: You can use this music literacy class in extracurricular music clubs to increase students' knowledge. Even at the moment of music literacy, the teacher should be able to set goals and objectives, be provided with equipment and methodological support!

\section{Course Outline:[5]}

Purpose: Use students to play the violin key elements.

Training equipment and teaching aids: Blackboard, exhibitions, tutorials and fun puzzles.

\section{Course of training:}

\section{Step 1: Provide students with theoretical information about the violin key.}

A special pitch is attached to and above the note lines to place the melody in the note path, and this is called a key.

The key is placed at the beginning of the note line on one of the main lines. In this case, one of the main lines must intersect the center of the key. The key assigns a specific sound or step height (name) to the note where it is located, and the location of the remaining sounds in the path of the note is also adjusted to that note.

There are three main types of keywords used in music today. One of them is the violin key.

The violin key is one of the keys to high (high), subtle sounds in music. Its second name is also called the "left" key. This is because the key is the "left" note on the 2nd line of the first octave note.

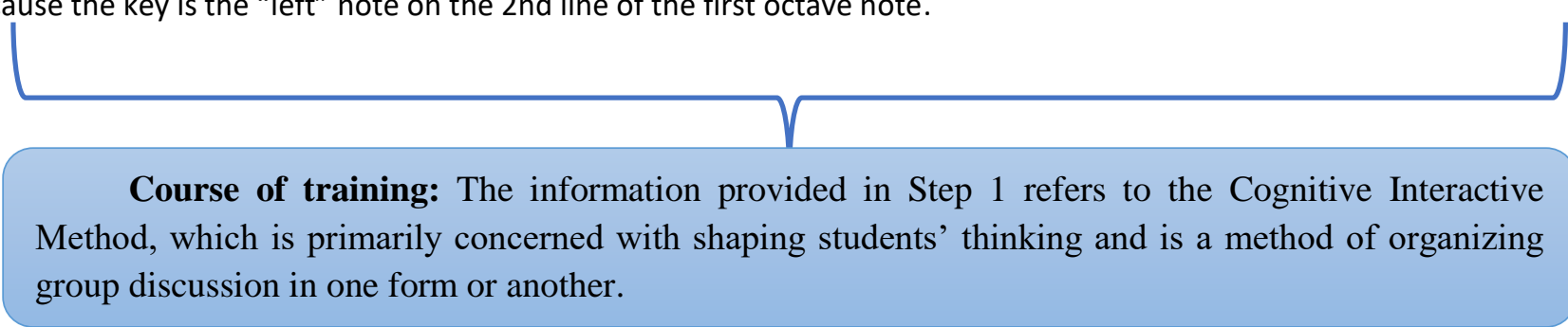

Step 2: Poetically explain, teach, and memorize the violin key to students.
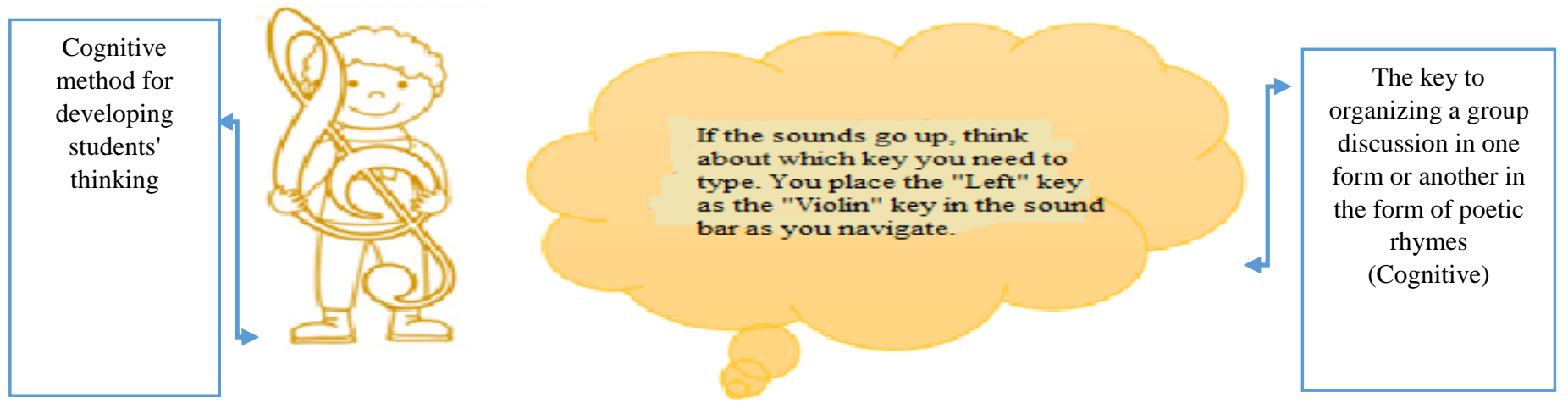
Interactive Methods in Shaping Music Literacy in Primary School Students

Step 3: Have students use the keys on the violin.

Dear reader! draw with a pencil on the given lines.

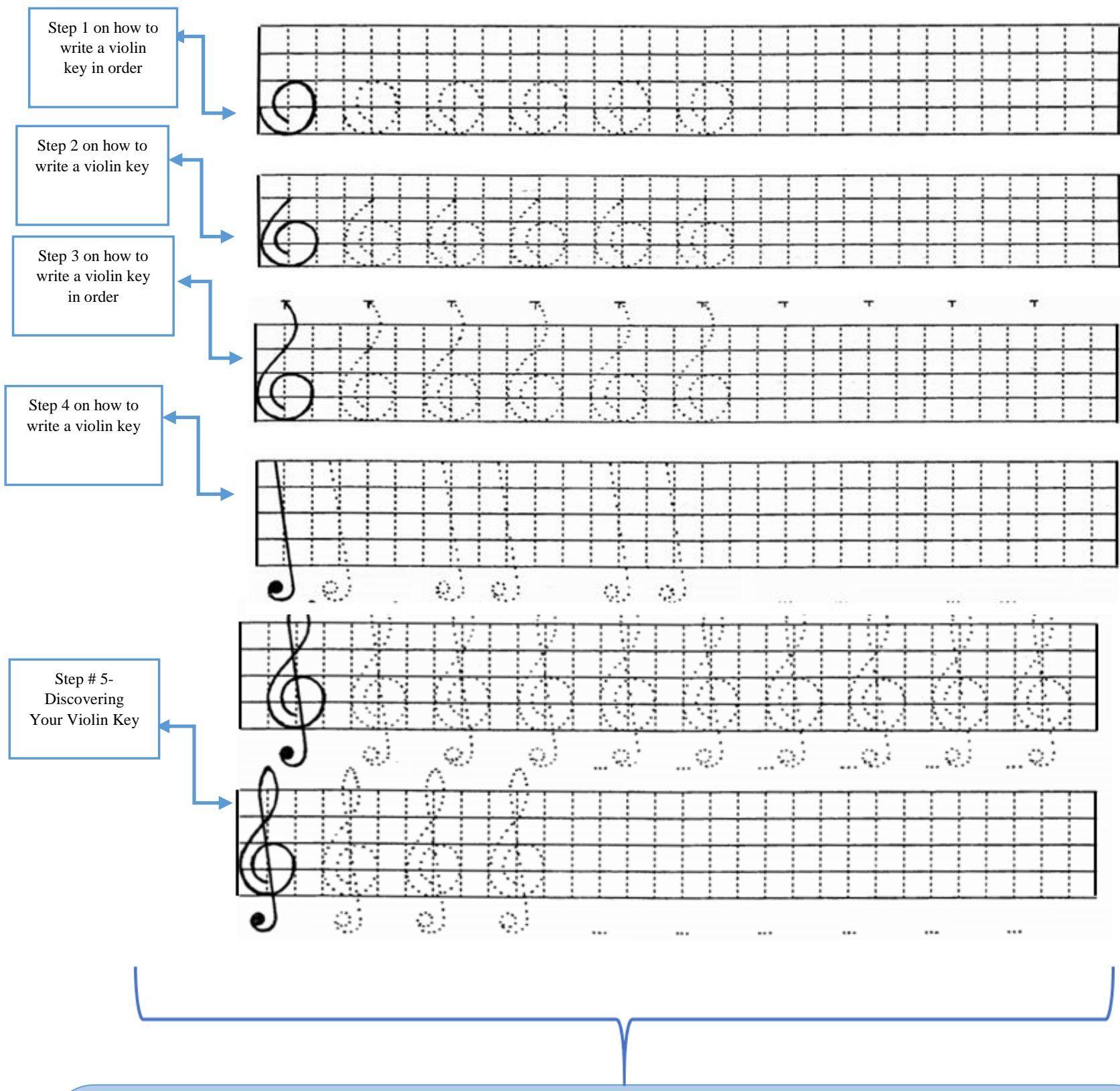

During the training: Poetry explanation, teaching and memorization of the violin key given in step 2-3, the use of students on the elements of the violin key are related to the interactive method of facilitation - the organization of group work, often clear, enters into a group of methods related to real tasks, discussion of decision-making, development of a realistic plan of action, organization of coordination of real, conflicting interests.

4-bosqich: “Qiziqarli boshqotirma” 


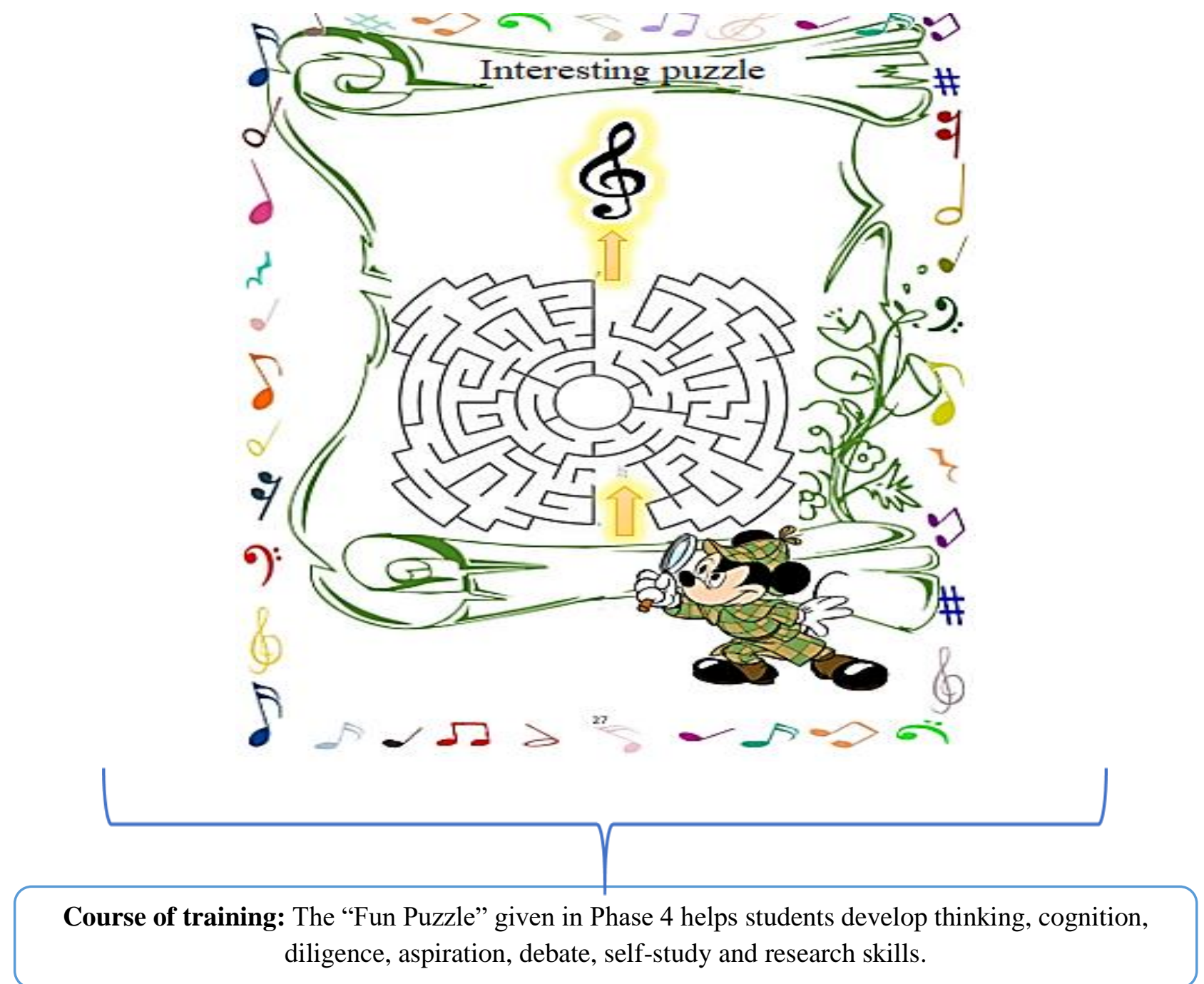

Step 5: Assess and motivate students.

\section{Step 6: Homework "Write the violin key independently!"}

Topic 10-11 of the 2 nd quarter of the 1 st grade music culture lesson on the topic "Violin key" and as an additional methodological aid in the minute of musical literacy recommended in the textbook and working on the elements "in the implementation of child-centered learning in teaching students based on interactive methods of Cognitive and Facilitation Cognitive (mental), it is very important to create conditions for communicative (speech communication), socio-emotional and physical-motor development. As a result of the use of interactive methods, students' skills of independent thinking, analysis, drawing conclusions, expressing their opinions, defending them on the basis of it, communication, discussion, debate are formed and developed. In this lesson, the above skills will help students to develop in a complex way and make the lessons meaningful, effective and, of course, interesting.

In summary, the American psychologist and educator B. Blum created a taxonomy of pedagogical goals in the cognitive and emotional fields and called it the "Bloom taxonomy". (taxonomy - the theory of classification and systematization of complex structured areas of existence). It divides thinking into six levels according to the development of cognitive abilities. According to him, the development of thinking takes place at the levels of knowledge, understanding, application, analysis, generalization, evaluation [6]. This means that our music literacy classes are directly and indirectly related to the Bloom's taxonomy.

\section{REFERENCES}

1) H.Nurmatov .N.Norkhojayev Textbook for 1st grade "Music". Gafur Gulam Publishing House is a creative house of printing. Tashkent: -2018 
Interactive Methods in Shaping Music Literacy in Primary School Students

2) "Music" calendar thematic plan for 1 st grade.

3) D. N. Rakhmonova "Music literacy of primary school students" textbook. Tashkent "Innovation-Intelligence"2020

4) Jorayev Khurshid Graduation thesis for a bachelor's degree in "Peculiarities of music education in secondary schools". Kokand State Pedagogical Institute. Kokand: - 2013

5) Primary School Music Literacy Handbook. Tashkent: "Innovation-Intelligence". 2020

6) Internet search engine. https://fayllar.org/3-mavzu-oquv-maqsadlarini-belgilash-mezonlari-blum-taksonomiya.html 